\title{
Dairy farm resilence in a variable environment
}

C. LEWIS ${ }^{1}$, C. STOLTE ${ }^{2}$ and E. STOLTE ${ }^{2}$

${ }^{1}$ Baker \& Associates, Masterton

${ }^{2}$ Wiltons Rd, Masterton

chris1@bakerag.co.nz

\begin{abstract}
Clarence and Elise Stolte farm the family Masterton property as 50:50 sharemilkers. They have made the 285 ha dairy farming business resilient to environmental and milk price volatility by remaining focussed on sustainable results and not productivity. Evidenced through the Dairy Systems Monitoring (DSM) and the Dairy Farm Business of the Year competition they stand in the top $10 \%$ of elite groups for financial results in both high payout in a high pasture yield season, and then in the following low payout, low pasture yield season. Being able to demonstrate consistent results comes from a deliberately well considered farm policy, skilled on-farm management, maximising home grown feed yields and strong discipline around the farm budget.
\end{abstract}

\section{Farm and business}

Clarence and Elise Stolte are 50:50 sharemilkers on the family dairy farm $5 \mathrm{~km}$ south of Masterton. Together the family business sustains a medium stocking rate (2.9-3.1 cows/ha), relatively high per cow performance operation $(400+\mathrm{kg}$ milksolids (MS)/cow) with low operating costs.

For the $2015 / 2016$ season they are farming 480 cows on a 165 ha platform with 120 ha as support land. This business is self-contained on 285 ha.

Clarence and Elise are participants in the Baker \& Associates Dairy System Monitoring (DSM) service which enables them to plan and monitor performance with benchmarking to compare their operation with peers.

The farm has 14 years of data recorded in this service. With this information it can demonstrate considerable resilience in a very challenging physical and financial environment.

- Annual average rainfall for the district is $969 \mathrm{~mm}$ per year. Actual rainfall for 2013/2014 was $1098 \mathrm{~mm}$ and for 2014/15 was $808 \mathrm{~mm}$ (Greater Wellington Regional Council data).

- The farm is partially irrigated but water restrictions invariably mean this farm is without irrigation for a period in most summers.

- The property calves in autumn and spring, milking all year round.

- There is a covered feed pad that enables the Stoltes to feed stock supplements in a controlled manner,

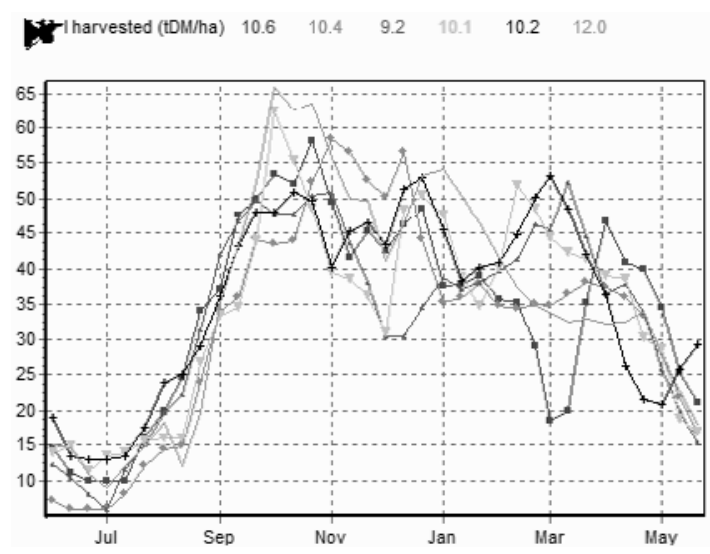

Figure 1 Pasture growth (kg DM/ha/day) profile from 2007 to 2013 on the Stolte farm, Masterton.

minimise damage in wet conditions and help to minimise the environmental footprint.

- Soils are stony silt with a shallow top soil.

- Pastures are prone to summer dry conditions and loss of desirable species.

Clarence and Elise have competed in the New Zealand Dairy Farm Business of the Year competition twice, both times winning third place nationally and awarded best business in the Lower North Island, and Best Medium/High Input Farm Business. They are past winners of the Wairarapa/Hawke's Bay Dairy Industry Awards Sharemilker of the Year section in the Dairy Industry Awards.

\section{Resilience}

Clarence and Elise have designed their operation around resilience. While there is scope to increase productivity, this has not been the focus. It is the ability of the business to consistently perform through a variable climate and volatile payout that has been the focus.

This has been achieved via a modest stocking rate, high per cow performance and active control of farm operating costs on behalf of the farm owner as well as their own sharemilking business.

How does the farm sustain performance in a variable physical environment?

Pasture growth from 2007 to 2013 is shown in Figure 1. As a summer-dry property the farm has a long history 
as a winter milk operation. The ability to dry cows off in early to mid summer, then calve in autumn takes pressure off the pasture at a critical time.

In recent years, pivot irrigation on half the farm with limited water has enabled the property to farm into early summer with adequate pasture. Reliability of the water has until now been an issue so the split calving policy has been retained.

Supplements are used to fill deficits in pasture production and the cows are wintered and summered away from the milking area.

\section{System design}

Table 1 presents the variation in physical and economic environment and how the Stoltes respond to manage this. For an insight into how the Stoltes have responded to the low payout forecast for the $2015 / 2016$ season, a modelled profile for this season has been included in the table.

Variation in pasture yield and changes in comparative stocking rate

In the 2013/2014 season, the Stoltes had excellent pasture yields (13.3 t DM/ha) with a good spring and irrigation water sustained for most of the summer

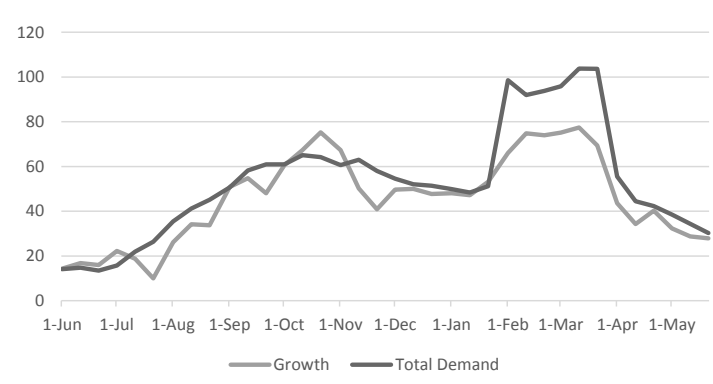

Figure 2 Pasture demand $v$ pasture yield (kg DM/ha/day) for 2013/2014 on the Stolte farm, Masterton.

(Figure 2). Ignoring the high payout, they chose to utilise this growth, not use supplements (DairyNZ System 2), but sustain high per cow performance at a low cost.

For the 2013/2014 season the comparative stocking rate was $75.5 \mathrm{~kg}$ liveweight $/ \mathrm{t} \mathrm{DM}$.

In the 2014/2015 season (Figure 3), the Stolte's farm was very dry, only growing $9.9 \mathrm{t} \mathrm{DM} /$ ha and feeding levels were altered resulting in a higher comparative stocking rate of $87.8 \mathrm{~kg}$ liveweight/t DM. Effectively the farm became a DairyNZ System 3.

\begin{tabular}{|c|c|c|c|}
\hline & 2013/2014 & 2014/2015 & $2015 / 2016$ \\
\hline Cows per ha & 3.1 & 3.0 & 2.9 \\
\hline Comparative stocking rate (kg liveweight/t DM) & 75.5 & 87.8 & 83.4 \\
\hline Pasture grown (t DM/cow) & 4.2 & 3.3 & 3.6 \\
\hline Supplement made (t DM/cow) & 0.7 & 1.1 & 1.1 \\
\hline Off- farm grazing (t DM/cow) & 0.6 & 0.7 & 0.7 \\
\hline Total offered (t DM / cow) & 5.5 & 5.1 & 5.4 \\
\hline Pasture grown (t DM/ha) & 13.3 & 9.9 & 10.8 \\
\hline Supplements made (t DM / ha) & 2.1 & 3.4 & 3.4 \\
\hline Off-farm grazing (t DM/ha) & 4.3 & 4.2 & 4.3 \\
\hline Total offered (t DM/ha) & 19.7 & 17.5 & 18.5 \\
\hline Brought-in feed/total feed offered (\%) & 8.8 & 19.8 & 16.6 \\
\hline Milk solids per cow (kg) & 439 & 381 & 422 \\
\hline Milk solids per ha (kg) & 1356 & 1126 & 1227 \\
\hline Feed offered per kg MS & 12.6 & 13.2 & 12.8 \\
\hline Payout - milk price only (\$) & 8.40 & 4.40 & 3.85 \\
\hline Operating cost $\left(\$ / \mathrm{kg} \mathrm{MS}^{1}\right)$ & 3.43 & 4.47 & 3.93 \\
\hline Operating cost ( $\$ / \mathrm{ha})$ & 4651 & 5033 & 4822 \\
\hline $\mathrm{EBIT}^{2} / \mathrm{ha}(\$)$ & 7073 & 386 & 317 \\
\hline DSM Group Average EBIT (\$) & 5146 & -153 & -198 \\
\hline Farm Rank in DSM Group & $4^{\text {th }}$ of 34 & $5^{\text {th }}$ of 36 & $5^{\text {th }}$ of 32 \\
\hline
\end{tabular}




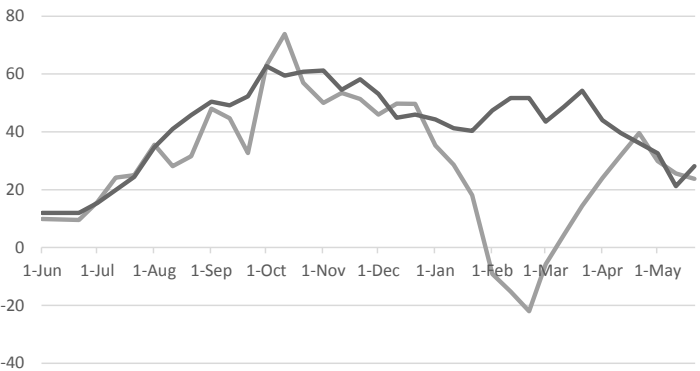

Growth Total Demand

Figure 3 Feed demand and pasture growth (kg DM/ha/day) for 2014/ 2015 on the Stolte farm, Masterton.

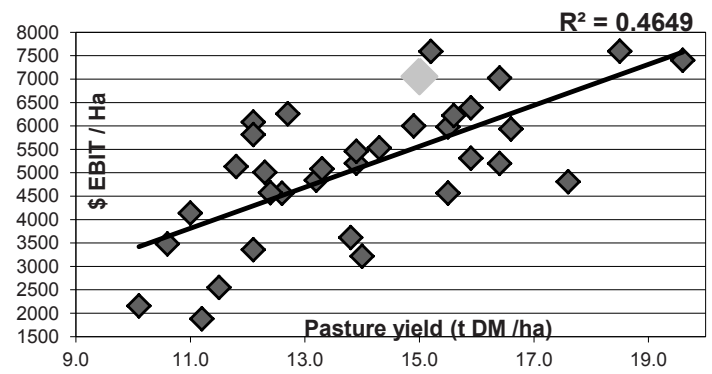

Figure 4 Pasture yield versus earnings before income and $\operatorname{tax}($ SEBIT) for 2013/2014

\section{Use of supplements}

In the dry season (2014/15) the drop in pasture yield necessitated more supplements to be used $(+62 \%)$, the ratio of feed brought to home-grown thereby making the farm a DairyNZ System 3 operation.

With the lower milk solids production in 2014/2015 farm operating costs increased $30 \%$ on a per $\mathrm{kg}$ milk solids basis, but only $8 \%$ on a per ha basis. This highlighted that an increase in feed and drop in production has a big impact on relative performance but the gross change in costs was relatively minor.

\section{How does this demonstrate resilience?}

The Stoltes have been able to sustain performance relative to their peers despite significant fluctuations in pasture yield and payout as shown in Figures 4 and 5 as pasture yield/ha versus \$EBIT (earnings before interest and tax) /ha and in Figures 6 and 7 which show operating costs per $\mathrm{kg}$ MS versus \$EBIT/ha. The Stolte's operation remains high for \$EBIT/ha despite significant changes in pasture production and milk solids payout.

For the 2015/2016 season the Stoltes are still expecting lower than normal pasture production (El Niño forecast), but with improved water reliability should grow more grass than the 2014/2015 season.

A further reduction in cow numbers has occurred

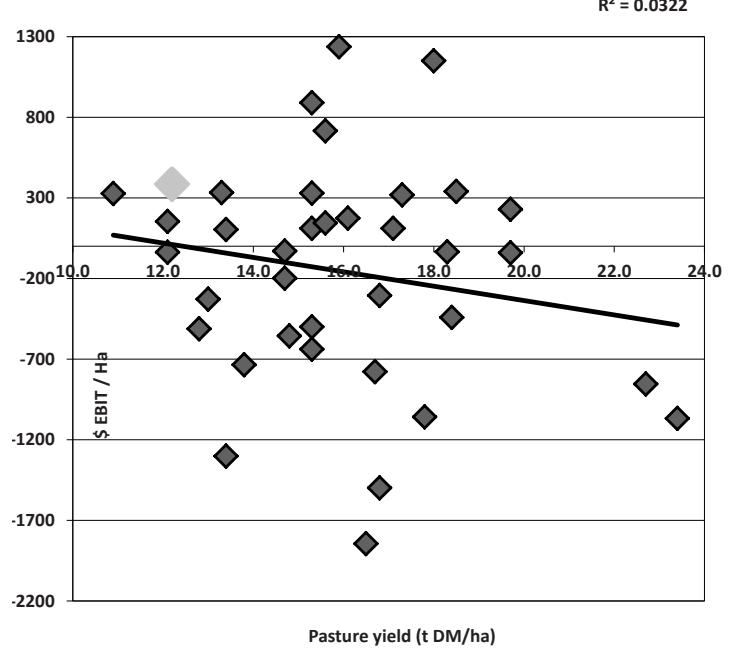

Figure 5 Pasture yield versus earnings before income and $\operatorname{tax}(\$ E B I T) /$ ha for $2014 / 2015$

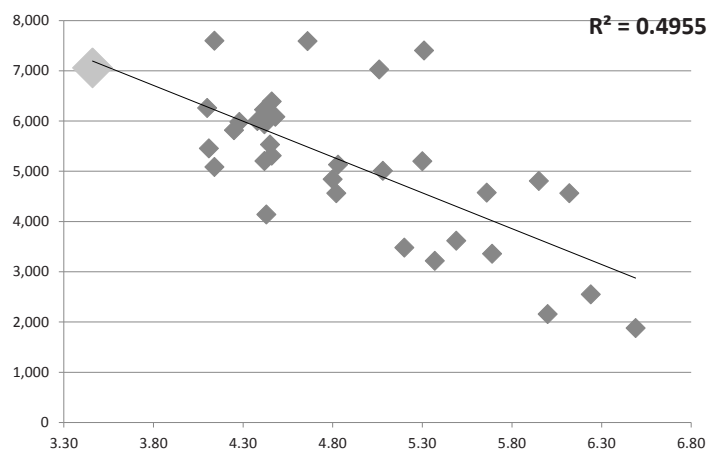

Figure 6 DSM: Cost of production (\$/kg MS) versus \$EBIT/ ha for $2013 / 2014$ at $\$ 8.40 / \mathrm{kg}$ MS

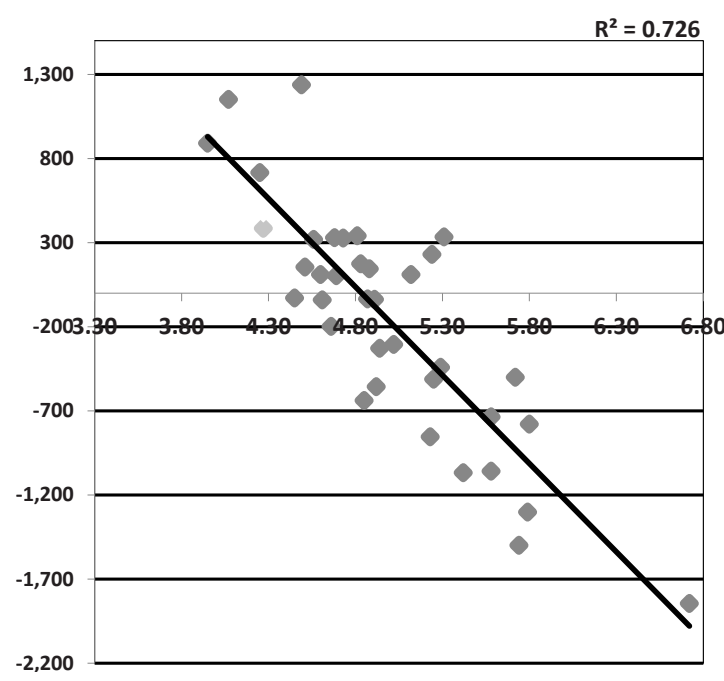

Figure 7 DSM: Cost of production (\$ $/ \mathrm{kg} \mathrm{MS)} \mathrm{versus} \mathrm{\$ EBIT/}$ ha for $2014 / 2015$ at $\$ 4.40 / \mathrm{kg}$ MS 
(2015/2016) with a view to getting the comparative stocking rate lower. This will aid the cost of production (lower than 2014/2015) and with higher production, help to offset the drop in milk solids payment.

\section{How does the farm sustain performance in a variable economic environment?}

The overriding system design and attitude towards cost control enables the Stolte family business to sustain high economic performance relative to its peers.

Simplicity in the operation is a key function. The Stoltes promote the matching of farm policy around infrastructure and labour. Over-extending the business leads to reduced operational efficiency and complications to the day-to-day management.

As an example, expansion of the business through leasing neighbouring land would require more labour which needs to be accommodated and/or the cowshed upgraded. More infrastructural cost undermines the gains in increased production.

\section{Keeping a low operating cost per kg milksolid.}

There is a clear and consistent protocol around operational costs and a budget that is adhered to.

Quantifiable inputs match required production and don't over-supply the system. Expenditure on imported supplements will occur such as in the dry period in early 2015. But essentially the production profile is totally connected to the budget profile and the budget directs expenditure like supplements instead of vice versa.

The financial plan is repeatable year-on-year. Changes are not made unless there is a clear and warranted gain. Animal health spending disciplines requires restraint from products offering marginal gain. The Stoltes stick to very basic animal costs. They vaccinate (lepto, rotovec, scour-guard), and they use magnesium, but don't use calcium supplements.

The Stoltes have learnt in previous industry downturns to challenge fixed costs. As an example insurance policies were scrutinised in detail. Areas where a claim would never occur, or the cover didn't warrant the expense, were cut from the insurance policy. This action saved $\$ 2000$.

Clarence has observed that it is not about high input versus low input. It is about having the right functional match of inputs.

\section{Key financial measures}

- The equity position of the total operation is $65 \%$.

- Return on total capital employed in the 2012/2013 season was $6.6 \%$ with a $\$ 6.16$ milk solids pay out. In the $2013 / 2014$ season on an $\$ 8.40$ payout it was $12.1 \%$. Note that capital includes the value of lease land.

- A further guide on why this business is resilient is the gross revenue to operating cost ratio. For the $2012 / 2013$ season gross revenue was 1.78 times the operating cost and for 2013/2014 gross revenue was 2.5 times expenditure. This presents significant scope to absorb a downturn in commodity prices.

\section{The team}

To consistently run the dairy farm at high end economic efficiency requires good physical farm management. To the Stoltes, this is about direction and leadership.

Good management is about maximising the growth and utilisation of home grown feed.

A top operational team understand what you want to achieve and are skilled at implementing the plan.

Weekly dashboard meetings are used to inform the entire team. The dashboard presents the plan in five areas.

- Cost tracker - monthly farm expenditure plotted against budget

- Focus areas (1-2 per month) - what do we need to achieve

- Key Performance Indicators are the measures used for performance, specific numbers on what we want to hit

- Health \& Safety - keeping the team safe

- Jobs list - primarily farm maintenance work that needs to be done.

\section{Business discipline}

Clarence and Elise are very clear about their farming philosophy. They run the farm at $80 \%$ of its potential with $40 \%$ of the operating cost keeping it tight and repeatable.

They are not tempted to employ unproven technology or inputs.

\section{Conclusions}

To be a resilient dairy farming business in a volatile environment you need to have good business disciplines connected to a well-designed farm system, and a good farm team.

The Stolte family business has designed an optimal system to match their annual pasture yields (range 9.9 to $13.3 \mathrm{t} \mathrm{DM} / \mathrm{ha} / \mathrm{yr}$ ) to farm infrastructure and managerial skill.

At 3.1 cows per hectare and $439 \mathrm{~kg} \mathrm{MS} / \mathrm{cow}$ delivering $1356 \mathrm{~kg} \mathrm{MS} / \mathrm{ha}$, using partial irrigation and a covered feed pad the largely self-contained business is an efficient property of medium to high per cow performance.

Comparative stocking rate ranges according to the season between 75 and $85 \mathrm{~kg}$ liveweight per tonne of DM offered. Farm operating costs are actively controlled around the budget and the season, not the pay out. The cost of production is contained within a 
narrow range of $\$ 4600$ to $\$ 5000 /$ ha. This is a variance of $9 \%$ when the milk price has varied $90 \%$ and pasture yield $34 \%$.

The business had a measured peer-reviewed return on capital of $12.1 \%$ in the $2013 / 2014$ season. This put them in the top $10 \%$ of New Zealand dairy farms and this benchmark result has been repeated over numerous years.

The combination of sustained high per cow production, a well-balanced stocking rate and low cost of production delivers sustained economic results in a volatile environment. The business discipline is to stick to the budget and be reassured that delivering at $80 \%$ of productive potential using $40 \%$ of potential expenditure delivers a resilient business.

\section{REFERENCES}

Baker \& Associates. Dairy Systems Monitoring Annual Report 2013/2014 and 2014/2015

Greater Wellington Regional Council. Rainfall data. http:/graphs.gw.govt.nz/ 
